\title{
DYEING OF ALKALI TREATED POLYESTER AND POLYESTER/ VISCOSE BLEND FABRICS AND CHARACTERIZATION OF THEIR PROPERTIES
}

S. M. GAWISH*, Y. A. YOUSSEF, M. F. SHAABAN, A. M. RAMADAN, S. M. ABO EL-OLA and R. FAROUK

National Research Centre, Textile Division, Tahrir Street, Cairo 12622, Egypt, *E-mail: samihagawish@yahoo.com

\begin{abstract}
The alkaline weight reduction of polyester and polyester/viscose blend fabrics and determination of the fabrics dyeing characteristics were evaluated. An alkali treatment of polyester and blend fabrics was carried out in a pilot scale mini jet machine using dilute caustic soda $(7 \mathrm{~g} / \mathrm{L})$ at 1:20 liquor ratio, in the presence of cetyl trimethyl ammonium bromide, a cationic surfactant $(1 \mathrm{~g} / \mathrm{L})$, as a reaction accelerator, at $120^{\circ} \mathrm{C}$. The weight reduction obtained was $16 \%$ for polyester fabric and 7.5 for the blend (7.5\% weight loss at 95 ${ }^{\circ} \mathrm{C}$ ). The alkali treated polyester fabric surface was examined using a scanning electron microscope.

The polyester fabric which has been subjected to alkaline hydrolysis was dyed in alkaline (pH 8.5) and acidic medium ( $\mathrm{pH} 4.5$ ), liquor ratio 1:20, using different Dianix, commercial disperse dyes, in a mini jet machine at and $120^{\circ} \mathrm{C}$. The results indicated that the alkaline dyed samples exhibited an increase of color strength and slightly better anti-crease property compared to the acid dyed and untreated control fabrics.

Dyeing of polyester/viscose blend fabrics was carried out in a single bath at $120^{\circ} \mathrm{C}$, in a mini jet dyeing machine using the conventional Forosol dyeing at $\mathrm{pH}$ 4.5. Alkaline weight reduction process improved the fabrics handle properties. Excellent to very good fastness results were observed for the dyed fabrics.
\end{abstract}

Key words: alkaline reduction; alkaline and acidic disperse dyeing; polyester; polyester/viscose blend; single bath blend dyeing.

\section{Introduction}

Nowadays, the market demands for silky-like polyester and polyester blend fabrics (viscose or cotton blends) is increased due to the rise in price of natural fibers such as cotton and silk. The textile industry was directed to the production and development of apparel and furniture garments made of polyester and cellulose blends.

Research studies were undertaken in the world for the alkali finishing and dyeing of polyester and blend fabrics to acquire a soft, light, silky handle, to prevent pilling 
and decrease antistatic effects of the fabric surface. Sheth et al. ${ }^{1}$ have investigated the characteristic changes of polyester and polyester/cotton blend fabrics during weight reduction using lab., batch, continuous and jet dyeing methods, for the akaline treatment in presence of a cationic surfactant. The different factors studied include weight loss, alkali concentration, hydrophilicity, pill formation, denier and tear reduction. Wicker et al. ${ }^{2}$ reported on the concepts for after treatment and dyeing of polyester/ cellulose yarns. Montazer $e$ al. ${ }^{3}$ has treated cotton/polyester fabric (50/50 \%) with $24 \% \mathrm{NaOH}$ at 60 and $90^{\circ} \mathrm{C}$ for different periods. This treatment improves the fabric properties such as moisture regain, water droplet absorbed and fabric pilling. Huseyin et al. ${ }^{4}$ worked on the dye selection for the alkaline, one step disperse/reactive dyeing of polyester/cotton blends. The effectiveness and environmental impact for the alkaline polyester dyeing and reductive clearing have been investigated ${ }^{5-6}$.

Gawish et al. ${ }^{7-14}$ have studied the alkaline finishing of polyester fabrics (also called alkaline saponification, hydrolysis or deweighing) in absence and presence of different specially synthesized cationic surfactants and polymers. The cationic surfactant was found to accelerate the alkaline reaction with nearly complete alkali consumption. The weight loss of fabrics, efficiency of the hydrolysis reaction, fibers tenacity as a function of temperature and reaction time in the presence of different cationic surfactants were evaluated.

A weight loss of $24 \%$ was attained ${ }^{15-19}$ for polyester fabric at a lab.scale, hydrolysed at $130^{\circ} \mathrm{C}$ in $40-60$ minutes using $10 \% \mathrm{NaOH}$ (owf), $1 \%$ cationic surfactant, which was prepared and compared to cetyl trimethyl ammonium bromide as a control cationic surfactant. Every terephthalate unit requires two moles of sodium hydroxide for the complete saponification reaction and the weight loss is equivalent to the quantity of alkali consumed in the reaction as follows:

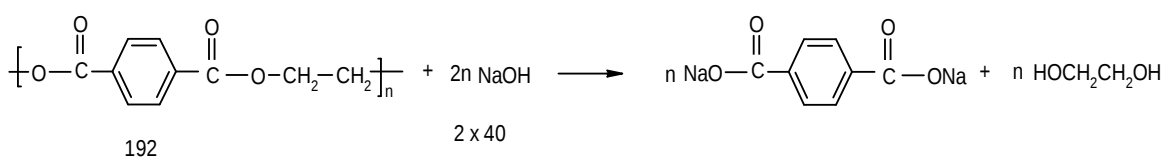

On the other hand, the effect of the alkaline weight reduction process on the dyeing of polyester has been studied. Imaruku ${ }^{20}$, Ibrahim et al. ${ }^{21}$ and Youssef et al ${ }^{22}$ have investigated at a lab. scale the alkaline dyeing system of polyester and polyester/cotton blend fabrics using sodium edetate. Boyadzhiev ${ }^{23}$ reported that the 
treated polyester with different degrees of weight reduction showed a slight decrease in color strength of the dyed and printed fabrics. Needles et al ${ }^{24}$ investigated that the weight reduced polyester fabrics gave a darker color and a slight color change compared to the untreated fabrics. Becheva ${ }^{25}$ demonstrated that by increasing the level of weight loss, the color strength was increased but the crock fastness of prints was reduced by $0.5-1$ grey scale unit.

In the present investigation we have proceeded for the alkaline hydrolysis, in a HT mini jet machine at a pilot scale Fig.1, of polyester fabric and blends, using dilute sodium hydroxide (7 gm/l) in presence of $1 \mathrm{~g} / \mathrm{l}$ cetyl trimethyl ammonium bromide at $120^{\circ} \mathrm{C}$ and 1:20 liquor ratio. A new alkaline dyeing process was adopted using a series of Dianix disperse dyes (DyStar Co.) at $\mathrm{pH} 8.5$ (with a mixture of borax /potassium dihydrogen phosphate), in the presence of Diaserver AD-85 as a stabilizing and buffering agent. Acidic dyeing of polyester at $\mathrm{pH} 4.5$ was done and compared to the alkaline dyeing.

Alkaline hydrolysis at $95{ }^{\circ} \mathrm{C}$ and dyeing of polyester/viscose blend fabric (65/35\%) was also investigated in a single step at $120^{\circ} \mathrm{C}$ and $\mathrm{pH} 4.5$ using Forosol dyes (Clariant Co.). The weight loss, fastness properties, dry crease recovery angle, surface roughness, pilings, electrostatic charges and mechanical properties were evaluated for polyester and blend fabrics.

\section{Experimental}

\section{Materials}

Scoured woven crepe polyester fabric 100\% $\left(167 \mathrm{~g} / \mathrm{m}^{2}\right)$ have been supplied by Egyptian spinning and weaving Co., Mehala El-Kobra, and polyester/viscose (65/35\%) twill blend fabric $\left(270 \mathrm{~g} / \mathrm{m}^{2}\right)$, was supplied by Stia Co., Alexandria, Egypt, were used.

Chemicals such as sodium hydroxide, borax, potassium dihydrogen phosphate, citric acid, glauber salt were all laboratory reagent grade.

Cationic surfactant, cetyl trimethyl ammonium bromide was supplied by Amresco Co., USA. Nonionic surfactant, nonyl phenol ethoxylate used for washing was supplied by ICI Co., England.

\section{Dyes for polyester fabric (DyStar Co. Egypt)}


0

Commercial alkali stable disperse dyes used are Dianix Yellow S-G, Dianix Rubine S-3B (CI Disperse Red 35), Dianix Blue S-BG and Dianix Orange S-G $200 \%$.

\section{Dyes for polyester /viscose blend fabric (Clariant Co., Egypt)}

Forosol Yellow PC, Forosol Rubinol PC, Forosol Grey PC, Forosol Navy HE and Forosol Brown PC.

\section{Dyeing auxiliaries:}

- Diaserver AD 85 , stabilizing and buffering agent, for the soft alkaline polyester dyeing at $\mathrm{pH}$ 8.5.(DyStar Co.)

- Sera Gel P-LP, anionic dispersing agent (DyStar Co.)

- Alba fluid, anti-crease (Ciba Co.)

- $\quad$ Respumit NF, antifoaming agent (Bayer Co.)

- Sand acid DSB, anionic, pH adjustment for the acid dyeing (Clariant Co.)

- Indosol ESO, cationic fixing agent for Forosol dyes (Clariant Co.)

\section{Methods \\ Pretreatment}

The fabrics were first washed with $2 \mathrm{gm} / \mathrm{L}$ nonionic surfactant at $60^{\circ} \mathrm{C}$ and liquor ratio 1:20 for $30 \mathrm{~min}$, rinsed, dried and pre-set at $190^{\circ} \mathrm{C}$ for 30 seconds on a stenter.

\section{Alkaline weight reduction process}

Weight reduction of polyester and polyester/viscose was carried out in a mini HT jet Longclose dyeing machine (Fig.1) at $120^{\circ} \mathrm{C}$ and liquor ratio 1:20 (100 liters/5Kg fabric), using $7 \mathrm{~g} / \mathrm{l}$ sodium hydroxide and $1 \mathrm{~g} / \mathrm{l}$ cetyl trimethyl ammonium bromide,a cationic surfactant for $60 \mathrm{~min}$. The treated samples were thoroughly rinsed with water, neutralized with $5 \%$ citric acid solution and dried. The fabric properties were tested prior to dyeing.

\section{Polyester dyeing}

Dyeing was carried out in a Longclose mini HT jet dyeing machine using various dye recipes at $120^{\circ} \mathrm{C}$ and liquor ratio $1: 20$. The soft alkaline dyeing of polyester fabric was carried out at $\mathrm{pH} 8.5$ using the following recipe: $\mathrm{X} \%$ (owf) Dianix disperse dye, 1.5\% Sera Gal PLP, 2\% of Diaserver AD-85, 2g /L Alba fluid anticrease, $0.2 \mathrm{~g} / \mathrm{L}$ Respumit NF antifoaming agent, $0.5 \mathrm{~g} / \mathrm{L}$ odour free carrier Sera Gal $\mathrm{PEW}$, a mixture of $2 \mathrm{gm} / \mathrm{L}$ borax and $1.5 \mathrm{gm} / \mathrm{l}$ potassium dihydrogen phosphate. The polyester fabric was introduced into the dyebath at $60^{\circ} \mathrm{C}$ and the temperature was 
raised at a rate of $2^{\circ} \mathrm{C} / \mathrm{min}$ to $120^{\circ} \mathrm{C}$, and the dyeing continued for $30 \mathrm{~min}$, after which, the dye bath temperature was reduced to $70^{\circ} \mathrm{C}$, and then the samples were neutralized with $5 \%$ citric acid rinsed thoroughly with water and dried (Fig.2).

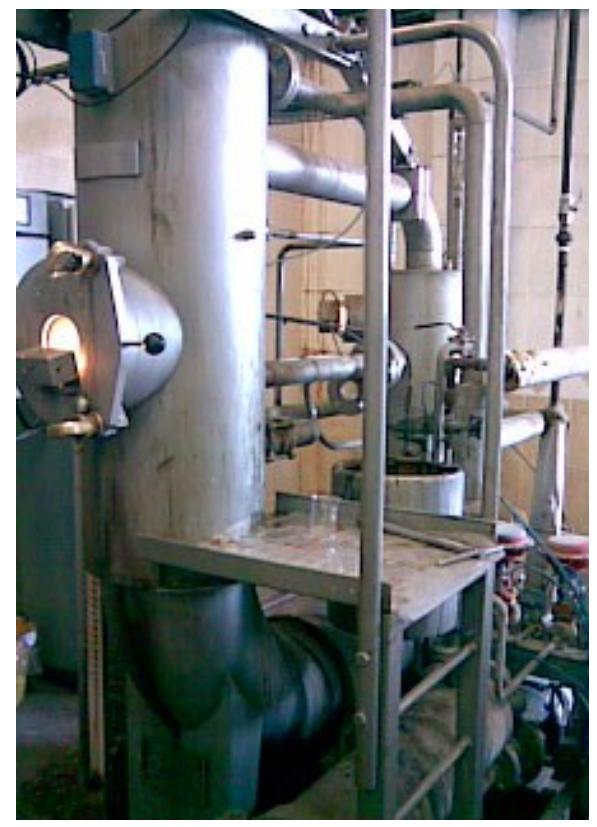

Fig. 1 Mini jet Longclose dyeing machine for alkaline reduction and dyeing of polyester and polyester/viscose blend fabrics

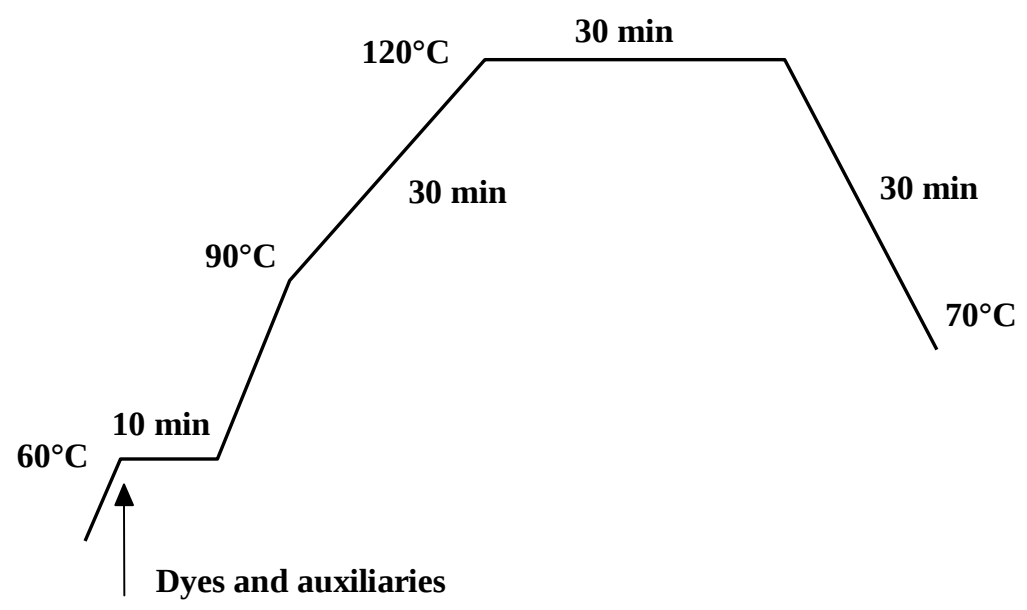


Fig. 2 Dyeing profile for alkaline reduction and dyeing of polyester and polyester/viscose blend fabrics

Following the dyeing profile shown in Fig. 1, the conventional dyeing method of polyester fabric at $\mathrm{pH} 4.5$ with $2 \mathrm{gm} / \mathrm{L}$ sand acid PSB was similarly performed using x\% owf Dianix disperse dyes, 1.5\% Sera Gal PLP, 2gm/L Alba Fluid anti-crease , 0.2 gm/L Respumit NF antifoaming agent and 0.5gm/L Sera Gel PEW carrier.

The alkaline and acidic dyeing processes were done forr the alkaline hydrolyzed fabric (16\% weight loss) and the properties compared to the untreated control polyester fabrics with the following four Dianix recipes (Khaki, Grey, Rubine and Blue colors):

$\mathrm{X} \%$ (owf) Kaki, combined Dianix dyes recipe:

0.39\% Dianix Yellow S-G,0.04\% Dianix Rubine S-3B and 0.02\% Dianix Blue S-BG $\mathrm{X} \%$ (owf) Grey, combined Dianix dyes recipe:

0.026 \% Dianix Orange S-G 200\%, 0.03 \% Dianix Rubine S-3B and 0.04 \% Dianix BlueS-BG

1.37 \% (owf) Dianix Rubine S-3B (Rubine), and 0.9 \% (owf) Dianix Blue S-BG .

\section{Dyeing of polyester/viscose blend}

The blend fabric (alkali reduced to $7.5 \%$ weight reduction) was dyed at $\mathrm{pH} 4.5$ in a single bath, adjusted with $2 \mathrm{~g} / \mathrm{l}$ Sand acid (Clariant Co.), at $120^{\circ} \mathrm{C}$ for $30 \mathrm{~min}$ as shown in Fig. 2. Dyeing was conducted with $\mathrm{x} \%$ owf Forosol dyes, 4gm/L Glauber's salt, 2 g/L Alba Fluid anti- creasing agent, 1.5g/L Sera Gal P-LP,0.2gm/L Respumit NF , 0.5 gm/L Sera Gel PEW. The dyed samples were rinsed, treated with $1 \%$ Indosol fixing agent at $70^{\circ} \mathrm{C}$ for $30 \mathrm{~min}$, after which the fabric is rinsed with water and dried at $120^{\circ} \mathrm{C}$.

Four combined Forosol dyes were used as follows:

$\times \%$ (owf) beige, Forosol dye recipe:

0.034\% Forosol Yellow PC, 0.022\% Forosol Rubinol PC, 0.04\% Forosol Grey PC $\times \%$ (owf) grey, Forosol dye recipe:

0.004\% Forosol Rubinol, 0.006\% Forosol Yellow PC, 0.06\% Forosol Gray PC $\times \%$ (owf) blue marine, Forosol dye recipe:

0.9\% Forosol rubinol PC, 2.9\% Forosol Navy HE

$\times \%$ owf Kaki, Forosol dye recipe:

0.06\% Forosol brown PC, 0.06\% Forosol Grey PC

\section{Testing}




\section{Color measurements}

The color strength (K/S) of the dyed samples were measured spectrophotometry. (Data color International SF 600 plus, D65) at the maximum absorption wave length for each dye $\left(\lambda_{\max }\right)$.

\section{CIELAB color system}

The CIELAB system uses three coordinates $\mathrm{L}^{*}$, $\mathrm{a}^{*}$ and $\mathrm{b}^{*}$ where $\mathrm{L}^{*}$ stands for lightness and ranges from 0 for black to 100 for white. A color (hue) can also be specified either in terms of the coordinates a* and b* (for grey and dull colors),

\section{Fastness properties}

The dyed samples were tested according to ISO standard methods. ${ }^{26}$ The specific tests were ISO 105-C02 (1989) for the washing fastness, ISO 105-E04 (1989) for color fastness to perspiration and ISO 105-B01 (1994) fastness to light using Sun test GPS , Atlas apparatus (Germany).

\section{Crease recovery angle}

It was done in the warp and weft directions using the iron recovery apparatus type FF-07 (Metrimpex).

\section{Surface roughness}

The surface roughness of the fabric was done using the surface roughness measuring instrument SE1700.

\section{Mechanical Properties}

Tensile strength $(\mathrm{kg})$ and percentage elongation were tested on the Instron instrument according to ASTM D 3822.

\section{Scanning Electron Microscopy (SEM)}

SEM was done for the untreated and alkaline treated polyester fabric (16\%weight loss) Fig.3. The samples were mounted on an aluminum device and sputter-coated with gold for microscopic examination at 3000-3500 X magnification

\section{Determination of pilings}

The fabric piling was determined on a ICI piling tester. The fabric sample was sewed on a rubber rod and allowed to rotate in the piling box for ten hours and the average view number of pilings was determined by a magnification lenses and compared to a standard image. 
17

4

(a)

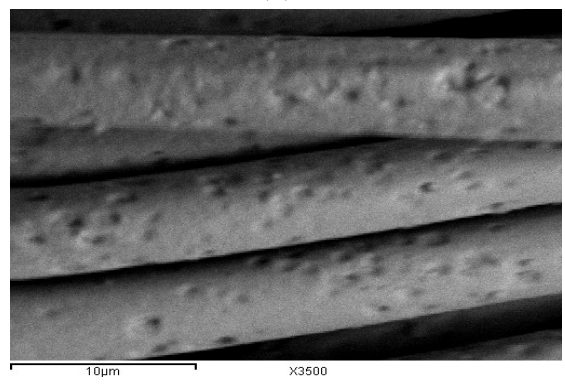

S. M. GAWISH, et al.

(b)

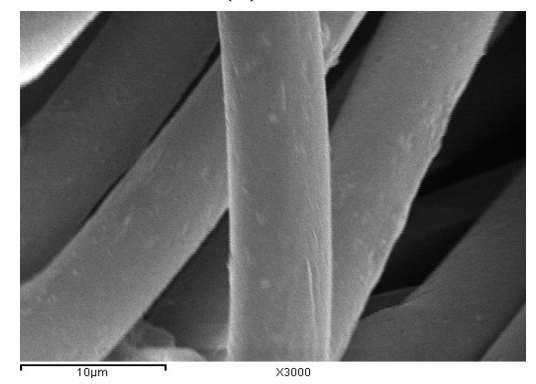

SEM

Fig.3 (a) alkali reduced PET fabric (16\% weight loss), and (b) control fabric.

\section{Determination of static charges}

The fabric static charges were determined using a hand collect electricity potentiometer type having a narrow scale which does not exceed $10 \mathrm{~K} \mathrm{~V}$.

\section{Results and Discussion}

\section{Effect of the alkaline reduction on the fabric properties}

The weight reduction, tensile strength loss, crease recovery angle and surface roughness of the polyester and polyester/viscose blend fabrics treated with $7 \mathrm{~g} / \mathrm{l}$ sodium hydroxide concentration in the presence of $1 \mathrm{gm} / \mathrm{L}$ cationic surfactant, cetyl trimethyl ammonium bromide, at $120^{\circ} \mathrm{C}$ are listed in Table 1 . The surface roughness of the fabrics has decreased as expected with the alkaline treatment and the percentage weight loss increased. The alkali treated fabrics show a loss in tensile strength for polyester fabric which is accompanied by a decrease in the fiber diameter as shown in Figure 3. A more pronounced decrease in tensile strength loss was observed for polyester/viscose blend at $95^{\circ}$ and $120^{\circ} \mathrm{C}$ compared to that of polyester fabric at $120^{\circ} \mathrm{C}$. This is mostly due to the increase in the weight loss of the viscose component in the blend. Also, the hydrophilicity of the blend fabric would be improved by the alkaline treatment as a result of increase of the viscose swelling and thus speeding up the surface hydrolysis of polyester component, resulting in an increase in the fiber softness.

The results of Table 1 also indicate that the percentage tensile strength loss is twice the fabric weight loss for polyester fabric. In case of polyester/viscose blend fabric, the tensile strength loss is fourth the percentage fabric weight reduction.

\section{Table 1}


Effect of alkali treatment of polyester and polyester/viscose blend on weight reduction, tensile strength loss, crease recovery angle and surface roughness.

\begin{tabular}{|c|c|c|c|c|}
\hline Fabric & $\begin{array}{c}\text { Weight } \\
\text { reduction } \\
\%\end{array}$ & $\begin{array}{c}\text { Tensile } \\
\text { strength loss } \\
\%\end{array}$ & $\begin{array}{c}\text { Crease } \\
\text { recovery } \\
\text { angle* }\end{array}$ & $\begin{array}{c}\text { Surface } \\
\text { roughness* } \\
\text { um }\end{array}$ \\
\hline PET & 16.4 & 30.6 & $301(295)$ & $17.9(20.6)$ \\
$\begin{array}{c}\text { PET/viscose } \\
\text { blend }\end{array}$ & 7.5 & 32.0 & $287(276)$ & $18.68(22.3)$ \\
\hline
\end{tabular}

$(*)=$ untreated fabrics

\section{Dyeing and fastness properties of the alkali treated polyester fabric}

The color strength K/S of the alkaline treated and untreated polyester dyed fabrics with Dianix dyes are shown in Table 2. The results revealed that the alkaline dyeing of the treated fabric give a higher color strength than the untreated samples. However, the untreated and conventionally dyed samples no 6 and 10 show better color strength values than those of the treated fabrics 8 and 12, respectively.

As a result of greater surface reflectance and better dye penetration, alkaline treated fabrics tend to exhibit higher color strength than untreated fabric. Also, the interior of the fiber becomes more accessible and dyes are able to diffuse more easily following the weight reduction treatment. An exception to this occurs under conventional dyeing of untreated fabric and the bigger diameter of the untreated fibres may suppress the dye to diffuse completely into the fiber. ${ }^{27}$

The colorimetric $\left(\mathrm{L}^{*}\right)$ refers to brightness-darkness with values from 100 to 0 representing white to black. The $\left(\mathrm{a}^{*}\right)$ values represent negative (green) to positive (red). The (b*) values are from negative (blue) to positive (yellow). The colorimetric data of the alkali treated and untreated polyester fibers dyed with Dianix Rubine S3B (Rubin color, CI35) at pH 4.5 (Conventional) and pH 8.5 (alkaline dyeing) are listed in Table 3. It can be seen that the $\left(\mathrm{L}^{*}\right)$ values of alkali treated/alkali dyed sample 7 and untreated/alkali dyed sample 5 decreased compared with those of the conventionally dyed samples 8 and 6 , respectively. Additionally, the (a*/b*) values are noticeably increased for the former samples 7 and 5 . This means that the color of such dyed samples become darker. 
Table 2: Color strength (K/S) of the alkali treated $100 \%$ PET (16\% weight loss), dyed with Dianix dyes at $\mathbf{p H} 8.5$ compared to the control, untreated and conventionally dyed fabrics

\begin{tabular}{|c|c|c|c|c|}
\hline $\begin{array}{c}\text { Dianix dye } \\
\text { (color) }\end{array}$ & $\lambda_{\max }(\mathrm{nm})$ & Sample No. & PET fabric & $\mathrm{K} / \mathrm{S}$ \\
\hline Kaki & 470 & $\begin{array}{l}1 \\
2\end{array}$ & $\begin{array}{l}\text { untreated } \\
\text { treated }\end{array}$ & $\begin{array}{l}6.80 \\
6.91\end{array}$ \\
\hline Gray & 640 & $\begin{array}{l}3 \\
4\end{array}$ & $\begin{array}{l}\text { untreated } \\
\text { treated }\end{array}$ & $\begin{array}{l}0.92 \\
0.98\end{array}$ \\
\hline Rubine & 530 & $\begin{array}{c}5 \\
(6) \\
7 \\
(8) \\
\end{array}$ & $\begin{array}{c}\text { untreated } \\
\text { " } \\
\text { treated } \\
"\end{array}$ & $\begin{array}{c}16.53 \\
(16.07)^{*} \\
17.89 \\
(15.88)^{*}\end{array}$ \\
\hline Blue & 640 & $\begin{array}{c}9 \\
(10) \\
11 \\
(12) \\
\end{array}$ & $\begin{array}{c}\text { untreated } \\
\text { " } \\
\text { treated } \\
\text { " }\end{array}$ & $\begin{array}{c}14.89 \\
(15.23)^{*} \\
15.72 \\
(14.86)^{*}\end{array}$ \\
\hline
\end{tabular}

* untreated and treated PET fabrics conventionally dyed at acidic $\mathrm{pH} 4.5$

Table 3 Colorimetric CIE $\mathrm{L}^{*} \mathrm{a}^{*} \mathrm{~b}^{*}$ of the untreated and treated polyester fabrics dyed using 1.37 \% (owf) Dianix Rubine S-3B (Rubin color, CI 35) at pH 4.5 (Conv.) and pH 8.5 (alkali) dyeing

\begin{tabular}{|c|c|c|c|c|c|}
\hline Treatment & Dyeing & Sample No. & $\mathrm{L}^{*}$ & $\mathrm{a}^{*}$ & $\mathrm{~b}^{*}$ \\
\hline \multirow{3}{*}{ Untreated } & Conv. & 6 & 34.29 & 49.38 & -4.17 \\
\cline { 2 - 6 } & alkali & 5 & 34.12 & 49.92 & -4.03 \\
\hline \multirow{2}{*}{ Treated } & Conv. & 8 & 33.87 & 47.95 & -3.30 \\
\cline { 2 - 6 } & alkali & 7 & 33.51 & 48.23 & -2.95 \\
\hline
\end{tabular}

Table 4 shows the effect of alkali treatment on the fastness properties of the alkali and conventionally acid dyed polyester fabrics compared to untreated samples.

The results indicate that the alkali hydrolysis had no effect on the washing, perspiration and light fastness. Excellent to very good washing and perspiration fastness were detected. The light fastness obtained was also similar irrespective of the treatment and the dyeing process. 
DYEING OF ALKALI TREATED POLYESTER

Table 4 Fastness properties of untreated and alkali treated polyester (16\% weight loss) which are dyed with Dianix dyes under both alkaline and conventional acid conditions

\begin{tabular}{|c|c|c|c|c|c|}
\hline \multirow{2}{*}{$\begin{array}{c}\text { Dianix dye } \\
\text { (color) }\end{array}$} & \multirow{2}{*}{$\begin{array}{c}\text { PET * } \\
\text { Sample No. }\end{array}$} & \multirow{2}{*}{$\begin{array}{c}\text { Washing } \\
\text { fastness } \\
\text { PET/C }\end{array}$} & $\begin{array}{c}\text { Fastness to perspiration } \\
\text { PET/C }\end{array}$ & $\begin{array}{c}\text { Alkalight } \\
\text { PET/C }\end{array}$ & \\
\hline \multirow{2}{*}{ Khaki } & 1 & $5 / 5$ & $5 / 5$ & $5 / 5$ & $7 / 8$ \\
& 2 & $5 / 5$ & $5 / 5$ & $5 / 5$ & $7 / 8$ \\
\hline \multirow{2}{*}{ Gray } & 3 & $5 / 5$ & $5 / 5$ & $5 / 5$ & $5 / 8$ \\
& 4 & $5 / 5$ & $5 / 5$ & $5 / 5$ & $5 / 8$ \\
\hline & 5 & $4 / 5$ & $4-5 / 4-5$ & $4-5 / 4-5$ & $7 / 8$ \\
\multirow{2}{*}{ Rubin } & $(6)$ & $4 / 5$ & $4 / 5$ & $4-5 / 5$ & $6 / 8$ \\
& 7 & $4 / 5$ & $4-5 / 4-5$ & $5 / 5$ & $7 / 8$ \\
& $(8)$ & $4 / 5$ & $4 / 5$ & $4-5 / 5$ & $6 / 8$ \\
\hline & 9 & $4-5 / 4-5$ & $4-5 / 4-5$ & $5 / 5$ & $5 / 8$ \\
Blue & $(10)$ & $4-5 / 4-5$ & $4 / 5$ & $5 / 5$ & $5 / 8$ \\
& 11 & $4-5 / 4-5$ & $4-5 / 4-5$ & $5 / 5$ & $5 / 8$ \\
& $(12)$ & $4-5 / 4-5$ & $4-5 / 4-5$ & $4-5 / 4-5$ & $5 / 8$ \\
\hline
\end{tabular}

* For key see Table 2

\section{Dyeing and fastness properties of polyester/viscose blend fabric}

The color strength K/S values of the blend fabric dyed with four different Forosol dyes combinations in a single step dyeing at $\mathrm{pH} 4.5$ and $120^{\circ} \mathrm{C}$ for $30 \mathrm{~min}$ are shown in Table 5. The alkali treated fabrics exhibited higher color strength values than the untreated samples. The increase in weight reduction may contribute to increase the hydrophilicity of the fabric. As a result, the dyes can diffuse more easily, improving the dye uptake of the alkali treated fabrics. These effects are pronounced with the different Forosol dyes combinations studied even with the darker blue marine color.

Table 5 Color strength (K/S) of the alkali treated and untreated polyester/viscose blend fabric conventionally dyed with different Forosol dye combinations at $\mathrm{pH} 4.5$

\begin{tabular}{|c|c|c|c|c|}
\hline $\begin{array}{c}\text { Forosol dye } \\
\text { (colo) }\end{array}$ & $\lambda_{\max }(\mathrm{nm})$ & Sample No. & $\begin{array}{c}\text { OET/Viscose } \\
\text { blend fabric }\end{array}$ & K/S \\
\hline Beige & 460 & 13 & untreated & 0.65 \\
treated & 0.66 \\
\hline Gray & 470 & 14 & untreated & 2.78 \\
& & 16 & treated & 2.91 \\
\hline Kaki & 640 & 17 & untreated & 0.63 \\
& & 18 & treated & 0.71 \\
\hline Blue Marine & 560 & 19 & untreated & 19.92 \\
& & 20 & treated & 20.76 \\
\hline
\end{tabular}


Similarly, the colorimetric data of the alkali treated and untreated polyester/viscose blend fibers dyed with Forosol dyes at pH 4.5 are listed in Table 6. It can be seen that the $\left(\mathrm{L}^{*}\right)$ values of alkali treated and dyed samples 14 and 20 are marginally decreased compared with those of the untreated dyed samples 13 and 19, respectively. Additionally, the $\left(a^{*} / b^{*}\right)$ values are slightly increased for the treated samples. This means that the dye uptake of the treated samples marginally increased.

The fastness results of untreated and alkali treated polyester/viscose blend dyed fabrics are shown in Table 7. The results indicate that the alkaline treatment had no effect on the washing, perspiration and light fastness of the dyed polyester/viscose blend fabrics. The washing fastness and perspiration fastness are excellent for all samples with exception of the Kaki color which showed very good ratings and very good light fastness is observed for all samples.

Table 6: Colorimetric CIE $\mathrm{L}^{*} \mathrm{a}^{*} \mathrm{~b}^{*}$ of the untreated and treated polyester/viscose blend fabrics dyed using Forosol dyes ( $\mathrm{CI}$ undisclosed ) at pH 4.5.

\begin{tabular}{|c|c|c|c|c|}
\hline Treatment & Sample No. & $\mathrm{L}^{*}$ & $\mathrm{a}^{*}$ & $\mathrm{~b}^{*}$ \\
\hline Untreated & 13 & 70.74 & 4.60 & 8.94 \\
\hline Treated & 14 & 69.88 & 4.68 & 9.06 \\
\hline Untreated & 19 & 21.18 & 7.01 & -14.88 \\
\hline Treated & 20 & 20.85 & 6.94 & -14.51 \\
\hline
\end{tabular}

Table 7 Fastness properties of the alkali treated and untreated polyester/viscose blend fabric dyed with different Forosol dye combinations at pH 4.5

\begin{tabular}{|c|c|c|c|c|c|}
\hline \multirow{2}{*}{$\begin{array}{c}\text { Forosol dye } \\
\text { (color) }\end{array}$} & \multirow{2}{*}{$\begin{array}{c}\text { PET/Viscose } \\
\text { Sample No. }\end{array}$} & $\begin{array}{c}\text { Washing } \\
\text { fastness } \\
\text { PET/C }\end{array}$ & $\begin{array}{c}\text { Fastness to perspiration } \\
\text { PET/C }\end{array}$ & $\begin{array}{c}\text { Alkaline } \\
\text { PET/C }\end{array}$ & Light \\
\cline { 4 - 5 } Beige & 13 & $5 / 5$ & $5 / 5$ & $5 / 5$ & $6-7 / 8$ \\
& 14 & $5 / 5$ & $5 / 5$ & $5 / 5$ & $7 / 8$ \\
\hline \multirow{2}{*}{ Gray } & 15 & $5 / 5$ & $5 / 5$ & $5 / 5$ & $7 / 8$ \\
& 16 & $5 / 5$ & $5 / 5$ & $5 / 5$ & $6-7 / 8$ \\
\hline \multirow{2}{*}{ Kaki } & 17 & $4 / 4-5$ & $4 / 4-5$ & $4 / 4-5$ & $6-7 / 8$ \\
& 18 & $4 / 4-5$ & $4 / 4-5$ & $4 / 4-5$ & $6-7 / 8$ \\
\hline Blue & 19 & $4 / 5$ & $5 / 5$ & $5 / 5$ & $6 / 8$ \\
Marine & 20 & $4 / 5$ & $5 / 5$ & $5 / 5$ & $7 / 8$ \\
\hline
\end{tabular}


DYEING OF ALKALI TREATED POLYESTER .......

179

* For key see Table 5 
0

\section{Pilings and static charges measurements}

The alkali treated and dyed $100 \%$ polyester fabric (blue and Kaki) showed no pilings at the fabric surface and this finding is in agreement with other published articles which are cited in the literature review ${ }^{9}$ The untreated and alkali treated polyester exhibited static electricity over $10 \mathrm{KV}$ and cannot be well determined due to the narrow range of the potentiometer $(0-10 \mathrm{KV})$.

The alkali treated and dyed beige PET/Viscose fabric (65/35 \%) shows a medium pilings effect compared to the untreated sample (high pilings) and there was no detection of static electricity.

\section{Conclusion}

Alkali hydrolysis of polyester fabric in HT mini jet machine using sodium hydroxide (7 g/l) in the presence of $1 \mathrm{gm} / \mathrm{L}$ cationic surfactant as an accelerator at $120^{\circ} \mathrm{C}$ was accompanied by $16 \%$ weight reduction and $30 \%$ loss in the tensile strength. In this procedure the sodium hydroxide concentration is low and the procedure is inexpensive compared to the conventional method using 170-180 gm/L caustic concentration and an accelerator , padding to 60-70\% steaming 3-5 min at 103 to $110^{\circ} \mathrm{C}^{6}$. It has been shown that the weight reduction process improves the surface roughness, prevent the pilings in case of $100 \%$ polyester, improves the pilings and prevents the static charges for PET/Viscose blend .Under alkali and conventional acid dyeing, the alkali treated polyester fabrics exhibited higher color strength compared to the untreated fabrics using different Dianix dye combinations. The dyed fabric is for thought to benefit from the increase in hydrophilicity and decrease in fiber diameter. The fastness results were all satisfactory for the different dye recipes examined.

Low levels of weight reduction for PET / Viscose bland (7.5\%) and tensile strength (32\%) were observed at $95^{\circ} \mathrm{C}$ and were dyed using four different dye combinations of Forosol dyes in single step process at $\mathrm{pH} 4.5$ and $120^{\circ} \mathrm{C}$. Increased levels of dye uptake were observed for the alkali treated blend fabrics and the fastness properties are high.

\section{Acknowledgement}

The authors would like to express their gratitude to the manager and staff of Anglo Textiles Co., Egypt for their kind cooperation during our work on the mini jet 
machine. The authors also gratefully acknowledge DyStar Co. and Stia Co. for providing the dyes and auxiliaries and the National Research Centre, Egypt for the financial support of the research.

\section{References}

1.SHETH, GEETAV, MUSALE, APARNA "Changes in characteristics of polyester and polyester/ cotton blended fabrics during weight reduction” AATCC Review, 5(10), 39-43 (2005).

2.NICOLAI W.,SCHOENFIELD A., "Polycotton concepts for the after treatment of polyester/cellulosics". Melliand International, 11(3), 254-257 (2005).

3.MONTAZER M, SEDIGHI A, "Treatment of cotton/polyester fabric in hot alkali media and reducing agent." India, 7-8, 454-459, Jan. (2005).

4.HUSEYIN A.E., PERKIN A., "Dye selection for alkaline one step disperse/ reactive dyeing of polyester/cotton blends" AATCC review, page 23-27 july (2004).

5.HUSEYIN A.E, PERKIN A., "Alkaline polyester dyeing and reductive clearing: Effectiveness and Environmental impact" AATCC review, page 21-25 (2005).

6.AUSTRALIAN TEXTILE CHEMICALS, "Innovative weight reduction technique." International Dyer, page 20-24, Febv (1999).

7.GAWISH S.M., MOSLEH S. AND .RAMADAN A.M., "Synthesis of a new cationic surfactant for the alkaline hydrolysis of solvent pretreated polyester fabrics. J.of Applied Polymer Science, 85, 1652-1660, (2002).

8.GAWISH S.M.,.KANTOUSH A. AND .MOSLEH S. "Alkaline Finishing of Polyester in the Presence of Ethoxylated Cationic Surfactant" Tinctoria, (10), 39-42,(1990).

9.GAWISH S.M AND .KANTOUSH A., "Factors Affecting the Saponification of Polyester Fabrics" Tinctorica, 87(5), 71-77(1990).

10.GAWISH S M. AND .KANTOUSH A.,"Quaternization of Tertiary Amine Surfactants and Study of their Surface Activity" Abstracted at The $7^{\text {th }}$ International Symposium on Surfactants in Solution, Ottawa, Canada (1988).

11.GAWISH S.M., .KANTOUSH A. AND .MOSLEH S., "Study on the Alkaline Saponification of Polyester Fabric in the Presence of Cationic Surfactants" Tinctoria, 85(11), 69-72(1988).

12.MOSLEH S, .GAWISH S.M., .KANTOUSH A. AND SHALABY S,E "Parameters for the Alkaline Saponification of Polyester Fabric" Tinctoria, 84 (12), 21-24 (1987).

13.GAWISH S.M. AND AMBROISE G., "Alkaline Hydrolysis of Polyester Fabrics" J.American Dyestuff Reporter, 75(2), 30-32 (1986).

14.GAWISH S.M., BOURGEOIS M.AND AMBROISE G., "Cationic Polymers for the Alkaline Saponification of Polyester Fabrics" American Dyestuff Reporter, 74 (12), 36-39 (1985). 
15.GAWISH, S.M., BOURGEOIS M. AND .AMBROISE G., "Cationic Polymers for the Alkaline Saponification of Polyester Fabrics" American Dyestuff Reporter, 74(11), 3536(1985).

16. GAWISH, S.M., BOURGEOIS M. AND AMBROISE G., "Effect of Cationic Surfactants on the Alkaline Hydrolysis of Polyester Fabrics" American Dyestuff Reporter, 75(7), 1924 (1986).

17.GAWISH S.M., BOURGEOIS M AND AMBROISE G., "Synthese du tri 2-hydroxyethyle cetyle bromure d'ammonium en tant qu'accelerateur pour 1'hydrolyse alkaline de tissue du polyester" Bull. Scient. ITF, 13(52), 27-34 (1984).

18.GAWISH, S.M.; BOURGEOIS, M.; AMBROISE, G. "New Quaternary Ammonium Surfactants for the alkaline Hydrolysis of Polyester Fabrics "American Dyestuff Reporter, 73(12), 37-42(1984).

19.AMBROISE, G.; BOURGEOIS, M.; GAWISH, S. M. "Les treatments alcalins des etoffes polyester" Bull. Scient. ITF, 13 (52), 25-26 (1984).

20.IMAFUKU H., "An alkaline dyeing system for polyester" J.S.D.C., Vol.109, p 350-352, Nov. (1993).

21.IBRAHIM, N. A.; YOUSSEF, M. A.; HELAL, M. H.; SHAABAN, M. F. J Appl Polym Sci, 89, 3563 (2003)

22.YOUSSEF, Y. A.; AHMED, NAHED S. E.; MOUSA, A. A.; EL-SHISHTAWY, REDA M. "Alkaline dyeing of polyester and polyester/cotton blend fabrics using sodium edetate" J. Applied Polymer Sc., Vol. 108, p 342-350 (2008)

23.BOYADZHIEV, P. Tekstilna Promishlenost, 30, 455 (1981)

24.NEEDLES, L. H.; HOLMES, S.; PARK, M. J"Exhaust dyeing of polyester-based textiles using high temperature alkaline conditions”. J.S.D.C., 106, 385 (1990)

25.BECHEVA, R. Tekstilna Promishlenost, 44, 10 (1996)

26.METHODS of Test for Colour Fastness of Textiles and Leather, 5th ed.; Bradford: SDC, (1990)

27.HILDEN, J. “ The effect of fibers properties on the dyeing of microfibers especial requirements in polyester microfiber dyeing”, ITB Dyeing/Printing/Finishing, , 3, 19 (1991)

28.RICHTER, P. Chemiefasern Textilindustrie, 41, E 129 (1991). 